\title{
Interdisciplinarity for Learning and Teaching Mathematics
}

\section{A Interdisciplinaridade no Ensino e Aprendizagem da Matemática}

\author{
Enrico Rogora* \\ ORCID iD 0000-0002-1268-8653 \\ Francesco Saverio Tortoriello** \\ ORCID iD 0000-0002-4600-6411
}

\begin{abstract}
Complex problems need interdisciplinary approaches. Thinking in an interdisciplinary way asks for changes in learning and teaching and hence in our views on pedagogical problems. An interdisciplinary approach could provide a new framework also for dealing with disciplinary didactical problems. In this paper, we propose a methodology which we call globally interdisciplinary laboratories as an effective way to practice interdisciplinary teaching at the high school level. We discuss the possibility of applying this methodology to the learning and teaching of mathematics. Globally interdisciplinary laboratories are designed by a pool of researchers in collaboration with high school teachers of several disciplines and they are delivered in the classroom by a pool of teachers in co-presence. This has been experimented in Italy in many classes which are part of a national educational project called Liceo matematico. In this paper, we discuss the general design principle of a GIL and exemplify the methodology by considering the one we have called educate the sight, which aims at stimulating, within an interdisciplinary framework, intellectual curiosity, the ability to spot the prominent features of a problem and, in mathematics, the ability of conjecturing, which should be one of the fundamental concerns of mathematical teaching, according to Polya's decalogue for mathematics teachers (POLYA, 1981).
\end{abstract}

Keywords: Interdisciplinarity. Didactics of mathematics. Learning mathematics.

\section{Resumo}

Problemas complexos precisam de abordagens interdisciplinares. Pensar de forma interdisciplinar exige mudanças na aprendizagem e no ensino e, consequentemente, em nossas visões sobre os problemas pedagógicos. Uma abordagem interdisciplinar poderia fornecer uma nova estrutura, também, para lidar com problemas didáticos disciplinares. Neste artigo, propomos uma metodologia que denominamos laboratórios globalmente interdisciplinares (GIL) como uma forma eficaz de praticar o ensino interdisciplinar no ensino médio. Discutimos a possibilidade de aplicar essa metodologia à aprendizagem e ao ensino da matemática. Laboratórios globalmente interdisciplinares são projetados por um grupo de pesquisadores em didática, em colaboração com professores do ensino médio de várias disciplinas, e são ministrados em sala de aula por um grupo de professores em copresença. Eles foram experimentados, na Itália, em muitas classes que fazem parte de um projeto educacional nacional chamado Liceo matematico. Neste artigo, discutimos o princípio geral de design de um GIL e exemplificamos a metodologia, considerando aquilo que chamamos de educar a visão, que visa estimular, dentro de um quadro interdisciplinar, a curiosidade intelectual, a capacidade de detectar as características proeminentes de um problema e, na matemática, a capacidade de conjeturar, que deveria ser uma das preocupações fundamentais do ensino da matemática, segundo o decálogo de Polya para professores de matemática (POLYA, 1981).

Palavras-chave: Interdisciplinaridade. Didática da matemática. Aprendizagem da matemática.

\footnotetext{
* Phd, Sapienza, University of Rome (Uniromal). Associate Professor, Sapienza, University of Rome (Uniromal), Rome, Italy. E-mail: enrico.rogora@uniroma1.it.

${ }^{* *}$ Phd, Università di Salerno (Unisa). Associate Professor, University of Salerno (Unisa), Fisciano, Italy. E-mail: fstortoriello@unisa.it.
} 


\section{Introduction}

In this paper, we discuss the theoretical framework of a research project in education, developed since 2014 by a group of researchers at the University of Salerno, under the scientific supervision of the Department of Mathematics, involving 8 distinct Departments ${ }^{1}$. We refer to this educational project as the "Mathematics as a Glue for Interdisciplinary Teaching" (MGIT) Project. This project stimulated the creation of the national network "Licei Matematici" in 2016 (AAVV, 2019), involving over one hundred high schools in Italy. In some of these schools, in the provinces of Avellino, Salerno, and Rome, the idea of building a highly interdisciplinary educational environment was developed, in which mathematics provides the main glue for connecting disciplines and making them interact profitably. The MGIT project aims at dealing with a nowadays sharp criticality in the teaching/learning processes: the need to provide students with the tools necessary to face complex and highly interconnected problems, typical of the contemporary world, which seldom receive proper attention in education (climate emergency, sustainability of development models, management of migratory emergency, just to name a few). We believe that this kind of problems cannot effectively be dealt with by means of a disciplinary or multidisciplinary approach, but they require a radically interdisciplinary one. ${ }^{2}$ One of the criticalities of teaching/learning models based on disciplines is the separation of science and humanities, especially with a marked division of their roles. Scientific disciplines for technical training and humanities for the education of the person. We believe that mathematics could play (and should play) a unique role to link in a fruitful, critical, and dynamical way scientific disciplines and humanities.

In fact, it has been observed that:

The cultural role of "corpus callosum", which connects the two hemispheres, is played by mathematics, which is humanistic in content, since it describes and creates possible worlds, but scientific in methods, since it uses logic (ODIFREDDI, 2000, p. 7-8). ${ }^{3}$

The two qualifying points of the MGIT Project that we discuss in this paper ${ }^{4}$ is the specificity of the gluing power provided by mathematics in education, already considered by (CAPONE, ROGORA, TORTORIELLO, 2017) and the proposal of a specific modality for

\footnotetext{
${ }^{1}$ Mathematics, Physics, Informatics, Chemistry, Humanities, Engineering, Economy, Education.

${ }^{2}$ By multidisciplinarity we mean juxtaposition of disciplines. By interdisciplinarity we mean developing strict relations between them and sharing of methodologies.

${ }^{3}$ All translations from non-English sources are provided by the authors.

${ }^{4}$ MGIT Project has other important goals, which will be not dealt with in this paper, like the revision of the mathematical curriculum of Italian high schools. It promotes, in particular, the consideration of topics directly linked with some of the complex problems we have recalled in the first section, among which probability (see (CAPONE, ROGORA, TORTORIELLO, 2017)) and statistical modeling.
} 
teaching/learning, that we call "globally interdisciplinary laboratory" (GIL), that is, in our opinion, a powerful teaching/learning mode aimed at the creation of fruitful, balanced, and critical interactions between disciplines. In this way, we have dealt with transversal topics that do not find their proper space in disciplinary based education models but that we consider are especially important in contemporary education. For example, "observational skills and intellectual curiosity", "knowledge management", "choosing in condition of uncertainty", "arguing and critically comparing different arguments in scientific debating".

Based on our experience, we got the conviction that globally interdisciplinary laboratories rise educational problems at an intermediate level between those considered by general educational theories and those considered by disciplinary ones. We believe that considering the disciplinary educational problem from the point of view of this intermediate level allows teachers to elaborate effective teaching strategies which are also helpful for the learning/teaching of a single discipline, as we shall try to argue in this work for the case of mathematics.

\section{Interdisciplinary learning/teaching}

Modern science bases many of its successes on the Cartesian method of splitting problems into smaller ones, which are easier to tackle. This model has proved to be very efficient to train people to solve specialized problems, which are not too complex. However, many warnings have been raised against the ultimate implications of this approach (MORIN, 1999), especially in education: knowing more by narrowing the object of investigation may lead to pulverization and finally to "knowing everything on nothing". Moreover, ultraspecialization in research could make science less effective in dealing with complex problems and, from a general cultural point of view, induces a dangerous form of illiteracy of the specialists, already pointed out by many thinkers.

Previously, men could be divided simply into the learned and the ignorant, those more
or less the one, and those more or less the other. But your specialist cannot be brought
in under either of these two categories. He is not learned, for he is formally ignorant
of all that does not enter into his specialty; but neither is he ignorant, because he is 'a
scientist,' and 'knows' very well his own tiny portion of the universe. We shall have to
say that he is a learned ignoramus, which is a very serious matter, as it implies that he
is a person who is ignorant, not in the fashion of the ignorant man, but with all the
petulance of one who is learned in his own special line (ORTEGA; GASSET, 1932,
p. 112)

A learned ignoramus is usually not concerned with the social role that a scientist and a teacher of science should assume in relevant debates concerning science and society and never 
takes the responsibility to warn against the undesired consequences of choices which may have an extraordinarily strong impact on everyday life and on the future of mankind such as, for example, climate change or pursuing unsustainable politics of unlimited growth for production and consumption. A learned ignoramus tends to limit their role to that of mere consultants on technical matters.

On the other hand, an approach to complex problems which pretends to do without a good knowledge of those scientific and technological aspects which are inextricably interconnected with them is ineffective, as dramatically shown in the speeches of some political leaders, who simply do not really control what they are talking about. How to change our educational systems to help people and society as a whole to deal effectively and responsibly with contemporary challenges?

In education, it has been observed that «the core of the idea of discipline is a social relation between the teacher and his or her disciples» (ALVARGONZÁLEZ, 2011). The dynamic of these relations is the object of the science of education and is the point from which we start our efforts for answering the question just raised.

As a decisive step towards an effective interdisciplinary education, we suggest in this paper instead of considering "social relations between the teacher and his or her disciples" "social relations between teachers and their disciples", where the crucial step is the shift of focus from a single teacher to a cohesive group of teachers with and within their classes. These relations may vary within an ample spectrum of gradation from "additive" to "globally interactive".

An example of additive relation is when at least two teachers in a classroom discuss how to coordinate the presentation of parts of their program to make students aware of their connections and appreciate them (second drawing in Figure 1). For example, the presentation of cultural and social reasons behind the emergency of perspective in renaissance painting can be very well coordinated with the presentation of the mathematical theory of vision, rediscovered in those same years. We call this kind of interaction multidisciplinary education.

On the other end of the spectrum, examples of what we consider as a globally interactive interaction between teachers and their classes, are those fostered by "globally interdisciplinary laboratories", that we shall discuss in chapter 4 . This we call global interdisciplinary education. 


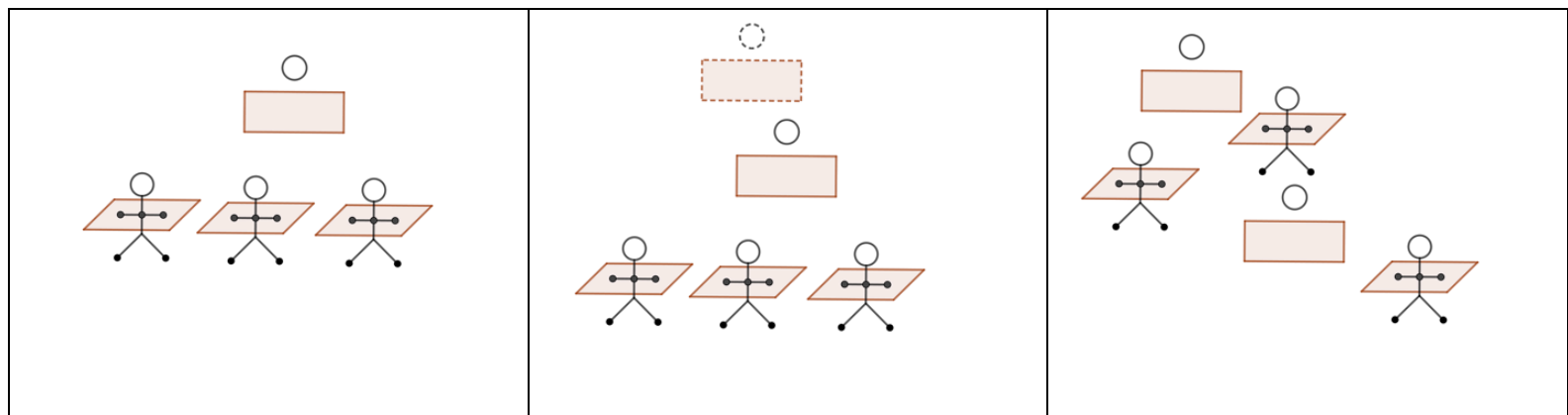

Figure 1 - Disciplinary, Multidisciplinary and Global Interdisciplinary Education Source: Image produced by the authors with GeoGebra

The qualification "global" is used to convey the idea that the interactions between the actors of the educational process that we are considering should be "complete". By this, we mean that in a Global Interdisciplinary Laboratory, students and teachers are required to exchange their role and collaborate between them as an organic whole (third drawing in figure 1). Our model is an idealized dynamic lecture resembling that described in (LAKATOS, 1976) but with the substantial addition of the presence of a plurality of teachers. The proposed interdisciplinary interaction between teachers and students in a Global Interdisciplinary Laboratory is characterized by a continuous exchange of roles. Some authors consider this autopoietic process necessary for an effective teaching.

Since the beginning of the teaching process, it is necessary that it becomes more and more evident a fact: despite the differences between them, the trainer is trained end re-trained along with the act itself of training, while a trainee is trained and, at the same time becomes a trainer (...) There is no teaching without learning (FREIRE, 2014, p. 20-21).

\section{The role of mathematics in interdisciplinary learning/teaching}

Learning/teaching mathematics is a difficult but especially important task in our society for many reasons, connected with economy, technology, science, and even democracy. In many countries, the problem of designing a good teaching of mathematics has become a national priority.

\footnotetext{
Most people believe that mathematics is a strategic matter for today's economy and certain studies claim, for example, that mathematics contributes for about $15 \%$ of the gross national product of France. We live in a period of extraordinarily accelerated changes: new knowledges; new technologies; new ways of communication - all directly connected with mathematics. Quantitative information, once reserved to specialists, is nowadays largely spread by media. The need to understand and use mathematics in every day's life and working has never been so urgent and it does not stop increasing. In a rapidly and continuously changing world, students need a solid background in mathematics. Mathematics provides essential instruments for an active citizenship. Mathematics is necessary for democracy since it favors autonomy and innovation (TOROSSIAN; VILLANI, 2018, p. 30-31).
}

Moreover, mathematics could and should play a more important cultural role in 
education. In fact,

mathematics has been a major cultural force in Western civilization. Almost everyone knows that mathematics serves the very practical purpose of dictating engineering design. Fewer people seem to be aware that mathematics carries the main burden of scientific reasoning and is the core of the major theories of physical science. It is even less widely known that mathematics has determined the direction and content of much philosophic thought, has destroyed and rebuilt religious doctrines, has supplied substance to economic and political theories, has fashioned major painting, musical, architectural, and literary styles, has fathered our logic, and has furnished the best answers we have to fundamental questions about the nature of man and his universe. As the embodiment and most powerful advocate of the rational spirit, mathematics has invaded domains ruled by authority, custom, and habit, and supplanted them as the arbiter of thought and action. Finally, as an incomparably fine human achievement mathematics offers satisfactions and aesthetic values at least equal to those offered by any other branch of our culture (KLINE, 1953, p. vii).

Unfortunately, it seems that the recognition of the cultural role of Mathematics proves hard to get off the ground, resulting in a substantial impoverishment of the educational value of the discipline itself and of all the disciplines which renounce upon the possibility of establishing rich and enlivening cultural relations with Mathematics.

Because of its fundamental role in shaping the world in which we live and of its centrality in western culture, a mathematically centered, interdisciplinary education is in our opinion particularly important. Mathematics, for its ability of abstracting and modeling interactions, provides, we think, the best glue for interdisciplinary teaching and learning (CAPONE; ROGORA; TORTORIELLO, 2017). Mathematical theories are enlightened by their applications and, in turn, a purely theoretical development in mathematics creates unexpected connections which provide new lenses for looking at the real world and approaching its understanding. Recognizing the essential role of mathematics for shaping our views of the world and for building useful models for developing technologies is a fundamental preliminary step on which our educational project is based.

Coming back to complex problems, mathematics is not only the fundamental glue with which to build an organic interdisciplinary teaching proposal, but it may also provide specific tools for modeling and analyzing complexity, which should find their space also in higher education curricula. This is not however of our concern in this work, even if we have designed specific activities to be carried out in high school in order to introduce some of these tools, namely globally interdisciplinary laboratories on probability thinking and climate emergency, in which we assign a paramount role to developing critical attitudes toward mathematization (ROGORA, 2014; DE MARCHIS; MENGHINI; ROGORA, 2020). 


\section{Globally Interdisciplinary Laboratories}

Globally Interdisciplinary Laboratories (GILs) are designed to tackle complex topics with strongly interdisciplinary character from a global interdisciplinary perspective. They constitute, in our opinion, the most innovative element of the MGIT Project.

To illustrate the characteristics of these laboratories we summarize the description of the general GIL characteristics in 4.1 and the contents and the aims of the GIL "Educate the sight" in 4.2 , in order to provide a concrete example. This is not a GIL that deals with a complex problem, but one which is designed for providing basic tools for dealing with complex problems, namely the habit of tackling problems in a collaborative way within a group of students and teachers, and the taste for intellectual curiosity. These tools, and those developed in the companion laboratory on "Educating to argumentation", provides a solid background for laboratories which tackles complex problems, like a GIL on probability thinking and the one on climate emergency.

\subsection{Designing a GIL}

The main characteristic feature of a GIL is the Interdisciplinary Teaching Unit (ITU). An ITU consists of a group of teachers of different disciplines which work together to carry out the GIL activities in one of their classes.

The structure of a GIL is not rigid. The nature of these laboratories is to promote a creative interaction between a class and their ITU. Therefore, each realization of a GIL is strongly characterized by the specific interaction that is established within an ITU and between the ITU and their students.

The main phases of a GIL are summarized in the diagram below. 


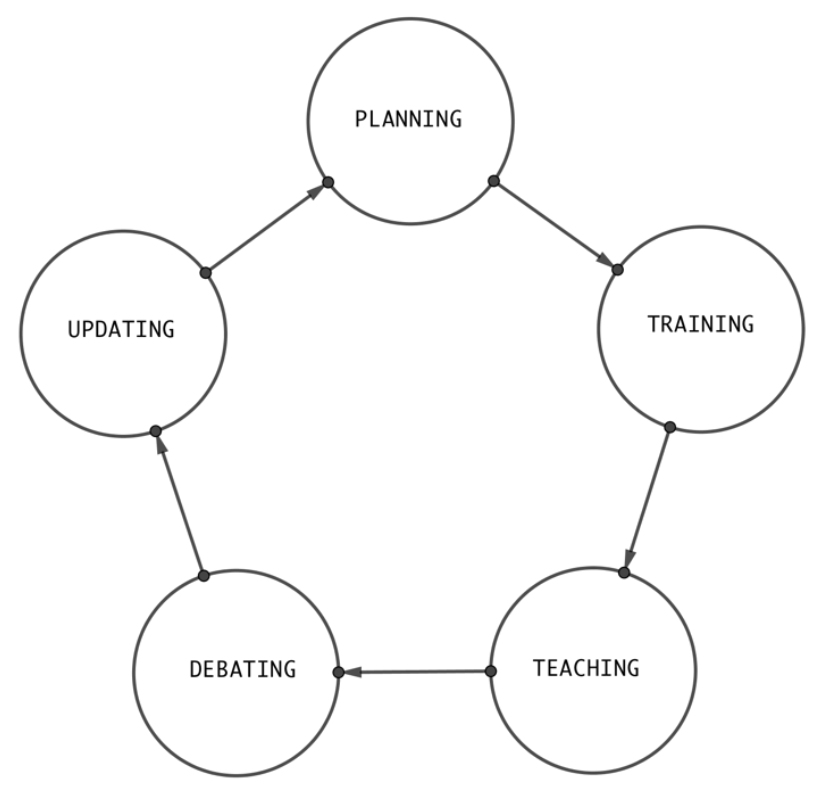

Figure 2 - Phases of a GIL

Source: Image produced by the authors with GeoGebra

We briefly comment on each of these.

Planning The choice of the topic does not follow any rule except that it must be a "transversal theme", declined differently in different disciplines. For example, in the "Educating the sight" laboratory, the theme of the transition from looking to seeing was chosen, which is transversal to mathematics and art (at least). In Mathematics: looking at a geometric configuration, looking for its properties and seeing its proof. In Art: looking at a painting, looking for its details and relationships, understanding its meaning. In the "climate emergency" laboratory, the theme is how to assess the risk and how to communicate it. The theme is transversal to mathematics, science, literature, language, philosophy etc.

Once the transversal theme has been chosen, an interdisciplinary working group of researchers and teachers of different disciplines is formed which assesses its interest, outlines its contours, seeks to involve people with the necessary disciplinary skills, and discusses its feasibility in the form of a laboratory to be brought to the classroom.

Teacher training During the planning phase, the critical points of the project are identified, regarding the disciplinary and interdisciplinary knowledge which teachers need to acquire, and the educational problems raised by the transposition of the GIL in a classroom. Training activities are planned for teachers by university researchers in the form of laboratories in which, in addition to providing theoretical insights, the activities that will later be brought in the classes are tested. The participation of teachers of different disciplines is crucial at this point since they will play both the role of teacher and student in the course of activities as they will 
be partly within their area of expertise and partly not. The experiencing of this continuous change of perspective stimulates vibrant and fruitful discussions which suggest new didactical ideas. This was recognized by participants as one of the main strengths of this approach.

The teacher training phase ends with the preparation of activity sheets for classroom activities. They are tried, discussed, and adapted by each ITU in collaboration with university researchers.

Teaching Each ITU carries out the GIL activities designed and tried during "teacher training" in their classes. It is crucial that each teacher of an ITU participates to each classroom activity. From the feedback forms that teachers collected from students, it appears that they appreciated to see their teachers discussing their activities in front of them and with them, and making consideration overstepping their subject area.

Debating At the end of the "Teaching" phase discussions are promoted between ITUs and university researchers on what emerged from the laboratories, whether the didactic objectives were achieved in a satisfactory way and as often happened, if the activities highlighted other objectives, not considered initially but worthy of development.

Updating The process ends with a rethinking of the laboratory, and with modifications or replacements of some activity sheets and the design of a new version of the laboratory itself, which follows the same general outline, but is profoundly renewed each year.

\subsection{The GIL "Educating the sight"}

We think that improving observational skills and fostering intellectual curiosity and active research attitude towards problems are examples of transversal activities that do not find their proper space in disciplinary based education models, but they are particularly important in contemporary education, for the following reasons:

1. Observational skills are useful for developing and sharing a global synthetic view of a complex problem i.e., for finding the "decisive abstract general relations" of a problem.

2. They provide a crucial step towards "education to the beauty" that we consider a crucial and neglected goal for contemporary education, which is especially important to promote for making people aware of the necessity to share and preserve beauty in all its form (beauty of nature, of historical and artistic testimony, of a balanced and harmonic lifestyle).

3. They help to deal with specific disciplinary educational difficulties. In 
mathematics, for example, developing observational skills may change students' approach to problems: «it became a good habit for my students to take a good look before trying to solve them, in order to let the problem speak to them and not fright them» (POSSAMAI, 2019).

The purpose of this GIL is to relate the activity of observing and interpreting a work of art with that of facing and solving a mathematical problem, to take advantage of the parallel observation of an art object and a mathematical problem. The laboratory compares the aesthetic pleasure of viewing an artistic work with the intellectual pleasure of dealing with a mathematical problem, underlining how these activities can be satisfying and of high educational value, even without necessarily leading to correctly interpret the work of art or to completely solve the mathematical problem, hence suggesting a possible way to help students to overcome the "I don't know what to do" syndrome. Reasoning and debating on these comparisons, suggests many activities which are not usual but of great educational value, both in teaching mathematics and history of art.

The idea of this laboratory arose from previous experiences of Valerio Vassallo and his collaborators at IREM in Lille (VASSALLO, 2018), from the reading of the writings of Federigo Enriques, Emma Castelnuovo and Bruno de Finetti on "knowing how to see" in mathematics (DE FINETTI, 1967) and from the reflections on the value and specificity of geometric intuition, as described in the works of Felix Klein and Federigo Enriques.

GILs on "Educating the sight", have been organized for three years, starting in 2016 in collaboration with art historians of the National Gallery of Palazzo Barberini and Palazzo Corsini, (GALLERIE NAZIONALI, 2020) within the project "con la mente e con le mani" (With mind and hands) of the Accademia Nazionale dei Lincei, which involved more than twenty schools in Rome.

Let us consider the general phases, described in subsection 4.1, for this GIL, especially dedicated to Teachers of Mathematics and Art and to first year high school students (14-yearolds).

Planning. The first planning of this GIL was made by Enrico Rogora (researcher in didactics of mathematics), Valerio Vassallo (researcher in didactics of mathematics), Michele Di Monte (art historian and responsible for educational activities for the National Gallery of Palazzo Barberini and Palazzo Corsini), Silvia Pedone (art historian), Francesco Sorce (art historian), Luigi Regoliosi (high school mathematics teacher) and Maria Cristina Migliucci (high school mathematics teacher). In this phase, a scheme for teacher training was designed, which envisaged a visit at Galleria Corsini, where it was planned to let teachers observe and 
discuss some paintings (see Fig. 3) and a "visit" to some interesting geometrical configurations (see Fig. 4), during which it was planned to let teachers observe and make conjectures on them, using the same activity sheet discussed below, in the paragraph "Teaching".

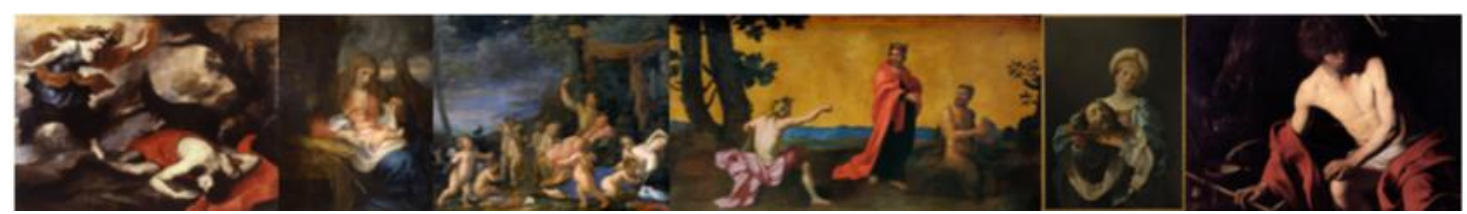

Figure 3 - The paintings discussed in teacher training. From left to right: Giuseppe de Ribera, Adone e Venere;Antoon Van Dyck, Madonna della Paglia; Nicolas Poussin, Il trionfo di Ovidio; Nicolas Mignard, Le jugement de Midas; Guido Reni, Salomé con la testa del Battista; Caravaggio; San Giovanni Battista. All pictures are in Galleria Corsini in Rome, except the fourth, which is in Palais des Beux Arts de Lille Sources: https://www.barberinicorsini.org and pba.lille.fr (fourth image from the left)

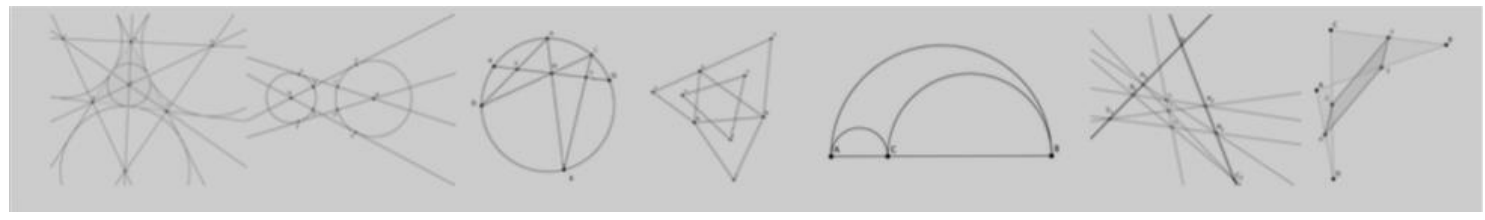

Figure 4 - The geometric configurations discussed in teacher training Source: Image produced by the authors with GeoGebra

Teacher training. This phase takes four/five meetings. The simultaneous participation of teachers of mathematics and history of art is required for each ITU, but teachers of other disciplines are welcomed. As we already said in 4.1, teachers of different disciplines working together on GILs foster the emergence of rich perspectives on educational problems raised by these activities: teachers of mathematics experience the student sight when they confront themselves with a work of art and the same is true for teachers of art when they confront themselves with a problem of mathematics. A teacher of mathematics said:

The experience at the Corsini Gallery allowed us to understand how the students feel in front of something they do not know how to interpret (for example the geometric construction necessary to prove a theorem): Why is important to understand the object I am considering? What are the essential details? Which ones are negligible? Am I following the right path or am I completely mistaken about the approach? (PERROTTA, 2019, p. 16-17).

Teacher training for this GIL is organized around the preparation and experimentation of the classroom activities discussed in the next paragraph (ROGORA, 2018).

Teaching The basic classroom activities for this GIL, grouped into two hours meeting and designed, tried, and discussed during teacher training, are succinctly the following:

- First Meeting: Two activities; the observation of Lloyd's star and the observation of a painting.

The activity based on Lloyd's star (See Figure 5) takes about fifteen minutes and has three purposes: to experience the difference between "seeing when looking" and "seeing when 
searching"; to link intuition to language, to become aware of the transition from looking to seeing; to experience the intensity of an intuition, in a way to be used as a touchstone for subsequent activities. For more details, see (IABICHINO, 2019).

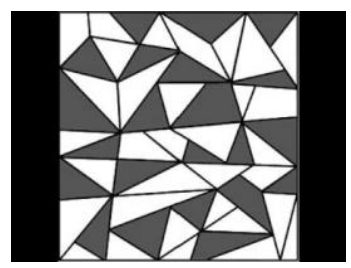

Figure 5 - The Loyd's star. Students are asked to describe what they see in the picture, then to look for a fivepoint star and finally to describe the strategy adopted to spot the star

Source: (LLOYD, 1914, p. 318)

The activity of observation and interpretation of a painting lasts about an hour and a half and uses an activity sheet in which students are asked to: collect the significant details of the painting; search for relationships; tell the story of what the picture means; give the picture a title. The painting used for this activity is the fourth in Figure 3, which is prone to many different interpretations, hence providing an intriguing challenge for the class. The title of the picture is not given in advance and students are asked to provide their own title. The activity has the purpose of experimenting and reflecting on the passage from looking to seeing in the context of the observation of a work of art. Students are first required to describe the details and the relationships between them that they spot in the painting. Then they are required to write the story which they think the painter wanted to tell. The separation of the observation and storytelling helps students understand the crucial importance of an in-depth observation. At the end of the work, done in pairs by the students, the art-history teacher coordinates a discussion on the different points and tries to sew, with the help of the class and of the other ITU teachers, the manifold narratives suggested by the students to arrive at one or more coherent interpretations. During the discussion, the teachers try to make the most out of each story told by students, even when they seem to lead to dead ends. Finally, the story of Midas' judgement is told (taken from the eleventh book of Ovidio's Metamorphosis).

The importance of the work done by each student in this activity, even if they did not interpret the painting "correctly", becomes evident in a second discussion activity about different interpretations of the same theme, given by other painters (se Figure 6), where students, as documented in post activity interviews, perceive a new awareness with which they look at a painting (IABICHINO, 2019). 


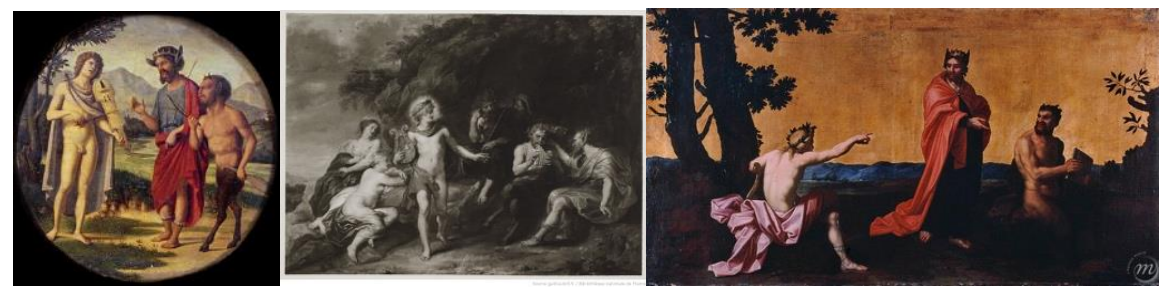

Figure 6 - The Theme of Midas' judgment in the works by Cima da Conegliano (left), Rubens and Mignard Sources: Wikimedia Commons (left); Gallica.bn.fr (center); pba.lille.fr (right)

- Second Meeting: The second meeting is dedicated to the observation and description of a geometric figure. Activities based on different geometric figures have been tested (see Figure 4). We briefly describe an easier one which uses the Tangram, which needs a minimum of prerequisites. The meeting is divided into two parts.

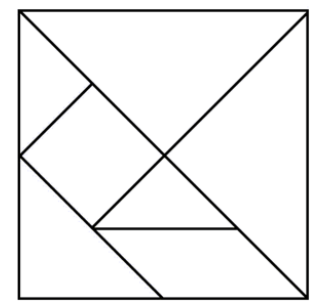

Figure 7 - How many figures can you see in the Tangram? Source: Image produced by the authors with GeoGebra

First part, lasting about an hour. An activity sheet is distributed in which students are asked to describe the figure and then read their description to the teacher to have it drawn. The activity sheet is structured in a way like the one used during the first meeting for guiding picture observation. This similarity is intended to stimulate the perception of the connection (and differences) between the two activities. Teacher follows the students' description, trying to highlight the ambiguities and assumptions implicit in the description, to stimulate them to become aware of the need for a precise description. We believe that too little time is given, when teaching mathematics, to description and construction of a geometric figure, but we believe that these are very formative activities that, if neglected, do not allow students to understand the sense of more complicated activities, such as those related to argumentation and demonstration. (IABICHINO, 2019).

Second part, lasting about an hour. The activity asks to count the figures that are seen in the Tangram. By stimulating students to look for more than the seven figures they spot immediately, a discussion begins on the definition of the concept of figure. The activity aims to bring out the hidden complexity behind a definition and the importance of considering definitions critically (IABICHINO, 2019). The activity is meant to highlight the component of freedom present in the work of the mathematician who "creates", through definitions, the worlds he studies. The observation that this activity shows a kind of freedom of mathematics 
has been suggested to us by a student during one of the first post-activity interviews.

- Third meeting. The third meeting is dedicated to an activity on the "first look" (to be completed in the fourth meeting) and to one on "demonstration without words".

The activity on the first look lasts a few minutes and is limited to presenting a problem that can be solved in several ways, and to ask that students, after reading and understanding it, write the first idea that comes to their minds to solve it, without worrying whether it is a good or a bad idea and if they would succeed to pursue it. The problems for this activity were selected by mathematics teachers during teacher training and tested with their non-mathematics colleagues. (IABICHINO, 2019).

The activity on "demonstration without words" lasts about an hour and guides the students into finding proof of the property of a geometric configuration starting from the clues that the class collects during the observation of a specially prepared figure. Figures were prepared with GeoGebra to allow students to move them, "putting ideas into motion" and making the class feel the importance of a dynamic approach to a problem.

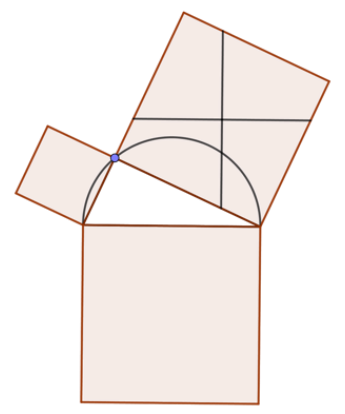

Figure 8 - The diagram for a proof without words of Pythagoras's theorem. Students were asked to "put the words" in the proof. Some of them saw the proof when they moved the blue points to the "highest point. Source: Image produced by the authors with GeoGebra

This activity suggests a parallel one in the observation of a painting, where we can try to "put ideas into motion" by moving "spatially" around the painting or moving "temporally" by comparing interpretations and reactions that the work has aroused over the centuries.

Also, the wordless demonstrations were selected by mathematics teachers during teacher training and tested with their non-mathematical colleagues.

- Fourth meeting. The fourth meeting, which is dedicated to completing the activity on the "first look", begun in the third meeting. The mathematics teacher, starting from the activity sheets collected during the activity on the "first look", discusses the first ideas of the boys, following all suggestions:-valuing those that indicate a feasible way to solve the problem; discussing the reasons why others do not work, especially if they may work in different situations. This way of proceeding is inspired by the discussion of details, 
relationships, and narratives, proposed in the activity of interpreting a picture described in the first meeting, to highlight how the collection of "clues", the verification of hypotheses, and the comparison of interpretations can characterize also mathematical activities and show that curiosity and the fun of understanding the meaning of a work of art can also be found in a mathematical activity (IABICHINO, 2019).

- Fifth meeting. Visit to an art gallery. Our GIL ends with a visit to the National Gallery of Ancient Art in Palazzo Corsini. Three paintings are shown to the class for discussion. The paintings are three among those which were shown to the teachers during teacher training (see Figure 3), who observed them with the help of the same activity sheet given to their students. Teachers discussed the paintings with the art historians who collaborated in the laboratory preparation and they chose the three pictures which had the most interesting remarks made by the teachers of each ITU during teacher training (the painting by Poussin was chosen by all ITU's). The discussion engages all teachers of the ITU and is organized very similarly to the discussions which took place during the previous meetings. This helps enhancing the perception of the unity of culture among students and their teachers, as pointed out in many post-activity interviews (IABICHINO, 2019).

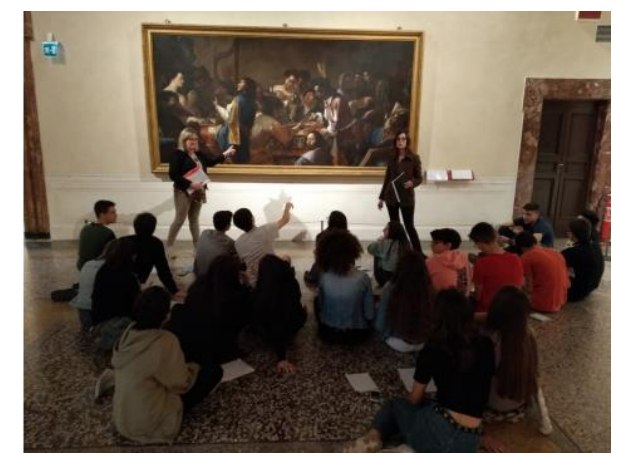

Figure 9 - In 2020, just before COVID emergency, we chose new paintings for the GIL "Educating the sight" at Galleria Barberini. The mathematics teacher (Elena Possamai, on the left) shares her comments on one of the paintings with their students and with the Art History teacher, Barbara Visca. The class is a second-year class at Liceo Nomentano in Rome where the GIL "Educating the sight" is now part of the activity for all classes, not only those of Liceo Matematico

Source: Elena Possamai Archive Photographic, authorized by the author

We believe that, with this kind of activities it is possible, to a certain extent, to "Educate the sight", stimulating curiosity to understand a painting and a mathematical problem through transversal laboratories, in situations that are not too characterized by the disciplinary point of view and are structured in such a way as to highlight analogies and differences. These activities are conceived to make students aware of the importance of language to make effective the transition from looking to seeing, both in art and in mathematics. They are not aimed at 
developing skills, but they are rather designed to stimulate transversal knowledge, to discover unexpected links between disciplines and to stimulate intellectual curiosity. It is a kind of teaching that does not easily find its place in contemporary Italian school because it does not place emphasis on specific "useful" skills, but on the 360-degree formation of the person.

According to their teachers, the most persistent attainment of students participating to this GIL, i.e., the attitude that remained through the years, is student's awareness of the importance of the observative phase in tackling a problem and the possibility to get hold of specific tools to enhance this ability, the most effective of which is the custom to share the look with other people using and developing a specialized language, specific to the problem under consideration.

\section{Interdisciplinarity and the teaching mathematics}

In our opinion, the interdisciplinary approach used in the design of Globally Interdisciplinary Laboratories helps not only to address cross-cutting issues from a correct interdisciplinary perspective, but also to address specific problems in the teaching of the disciplines involved, specifically in mathematics. In this last section, we want to give an idea of how some important key concepts of research in mathematics education can be approached within an interdisciplinary frame in globally interdisciplinary laboratories.

\section{The language of mathematics}

It has been observed by several authors that some of the difficulties of learning mathematics can be usefully addressed from the perspective of learning difficulties in a specialized language:

Learning mathematics may now be defined as an initiation to mathematical discourse, that is, initiation to a special form of communication known as mathematical. (SFARD, 2001, p. 28)

This point of view is close to one of the aims of the GIL "Educating the sight", which highlights the importance of the communicative context and encourages the comparison between different languages, facilitates the analysis of their relationships and helps motivating and making the transition from a common language to a specialized one easier. According to this perspective, the language of mathematics does not appear unnatural but deeply connected to other specialized forms of languages. 


\section{Fear of making mistakes and the importance of errors}

There is no discipline in which the fear of error is so strong and rooted as in mathematics.

It is evident that the demonization of error in mathematics has significant effects on an emotional level. (...) The spread of the fear of making mistakes, turns out to be the emotion most associated with mathematics (...) the effects of the fear of making mistakes, [result] on the block of thought processes (BACCAGLINI FRANK; AL, 2018, p. 67).

The activities proposed in the GIL "Educating the sight" indicate a way to manage the fear of making mistakes, trying to remove the anxiety caused by the pressure of always saying the right thing and recognizing the fundamental value of errors in learning. In comparison with the activity of interpreting a painting, the worry of always doing the right thing, typical of mathematics, appears less acute. Looking at a painting turns out to be rewarding even if one cannot interpret it: is it possible to get some satisfaction when considering a mathematical problem even without being able to solve it? Satisfaction and rewards may be obtained by realizing the importance of achieving partial but significant educational objectives like describing the situation (for example a geometric configuration) correctly, transforming the problem into a different but equivalent one, understanding the possible ways for generalizing a problem, seeing how to connect it to some other problem, etc.

Learning how to cope with errors is fundamental.

To avoid error is a poor ideal: if we do not dare to tackle problems which are so difficult that error is almost unavoidable, then there will be no growth of knowledge. In fact, it is from our boldest theories, including those that are erroneous, that we learn most. Nobody is exempt from making mistakes: the great thing is to learn from them (POPPER, 1972, p. 186).

Working with teachers of different subjects, positively impressed students since they got a chance to look at their teachers making mistakes but also being able to use them to further their understanding.

\section{Arguing, interpreting, and demonstrating}

One of the critical points in teaching/learning demonstrations concerns the obscurity of their functions:

The students' difficulties in the demonstration approach cannot be explained exclusively in cognitive terms of deficiencies in logical reasoning but related to the difficulty of attributing a clear function to the demonstration (DE VILLIERS, 1990, p. 17).

In the GIL "Educating the sight", and in a more complete way in the GIL "Educating to argumentation" (PUZIO; SAVINELLI, 2019), the development of parallel interdisciplinary activities aims at clarifying the function of demonstrations. For example, the activity of 
interpreting a work of art compared to that of demonstrating a conjecture concerning a geometric figure is structured in such a way as to highlight the connections between them and make students actively participate in the process of making sense of a conjecture, sharing the interest in arguing about it, building a shared proof of it. This parallel structure naturally highlights the social role and the social value of demonstrations, a crucial point to be considered for making sense of their teaching and learning, also according to (STYLIANIDES, 2007).

\section{Overcoming the blocks "I don't know what to say", "I don't know what to do"}

Too often a student's first reaction to a math problem is dichotomous: «I can do it because I have already seen a similar one» (and therefore the problem should be better called an exercise) or «I can't do it because I've never seen anything like it before».

In the GIL "Educating the sight" we look for tools for facing the difficult moment of the first approach to a new problem in a more conscious and active way.

The activity of making explicit the "first glance" to a problem, which consists in writing precisely the first idea that comes to mind to tackle a problem, without developing it until its solution and the subsequent activity required of teachers to discuss and with the whole class the various suggestions, helps to appreciate the mathematical work regardless of the result that is immediately achieved and to realize the existence of different possible general strategies to face a problem that can be effectively employed before throwing in the towel (studying special cases, replacing the problem with a simpler one, generalizing the problem, linking it to a problem already seen, highlighting the common and specific elements, transforming a geometric problem into an arithmetic problem or vice versa, etc.)

Look out for such features of the problem at hand as may be useful in solving the problems to come - try to disclose the general pattern that lies behind the present concrete situation. (POLYA, 1981, part II, p. 116).

\section{Conclusions}

This paper discusses a methodology for interdisciplinary work, and discusses one of its realizations, the GIL "Educating the sight". Other GILs have been designed in the framework of the educational project "Licei Matematici". These are "Educating to argumentation", which develops an introduction to mathematical proof in the historical context of the emergence of argumentation in Greek society, "Govern uncertainty" on probabilistic reasonings and "Climate emergency", on the need and limitations of mathematical models for scientific forecasting and the difficulties to communicate science in society. The GIL "Educating the sight" and 
"Educating to argumentation" are designed for providing basic tools for interdisciplinary education and for developing the habit of joint work between students and teachers in copresence. It is not easy to find teachers willing to work in co-presence in all the phases of a Global Interdisciplinary Laboratory, but all those who joint one of our GILs considered this way of working very stimulating and useful in class, especially for a continuous change of perspective in their work, which suggests many didactical activities, well beyond the framework of a given GIL. Moreover, students find very profitable to work with teachers in co-presence for three main reasons at least. First, the interactions between teachers working in co-presence makes it possible to highlight links between different disciplines much more vividly than when the interaction is with an individual teacher, and therefore reinforces the perception of the unity of culture and the interdependence between them. Second, many students reported the effectiveness of the mediating role of teachers between the class and the reference teacher in disciplinary activities. For example, in various mathematical activities, the intervention of nonmathematical teachers often succeeds in giving a clearer voice to the doubts and difficulties of the class and easing the process of learning. Finally, GILs have proved to be very stimulating and effective in highlighting the links between schoolwork and complex problems of our society, not only for being informed about them but also for becoming aware of the tools available to face and how to share them in a collaborative, synergic work.

\section{References}

AAVV. Licei matematici. Tratto da Benvenuto al Liceo Matematico. 2019. Available in: https://www.liceomatematico.it. Access on: 06/29/2021.

ALVARGONZÁLEZ, D. Multidisciplinarity, Interdisciplinarity, Transdisciplinarity, and the Sciences. International Studies in the Philosophy of Science, [s.1.], v. 25, n. 4, p. 387-403, 2011.

CAPONE, R.; ROGORA, E.; TORTORIELLO, F. S. La matematica come collante culturale nell'insegnamento. Matematica, Cultura e Società. Rivista dell'Unione Matematica Italiana, Bologna, v. 2, n. 3, p. 293-304, 2017.

BACCAGLINI FRANK, A.; DI MARTINO, P.; NATALINI, R.; ROSOLINI, G. Didattica della Matematica, Firenze, Mondadori Università, 2018.

DE FINETTI, B. Il saper vedere in matematica. Torino: Loescher, 1967.

DE MARCHIS, M.; MENGHINI, M.; ROGORA, E. The importance of extensive teaching in the education of prospective teachers of mathematics. In: $1^{\text {th }}$ Conference of Applied Mathematics, APLIMAT 2020 Proceedings, Bratislava, p. 101-118, 2020.

DE VILLIERS, M. D. The role and function of proof in mathematics. Pythagoras, [s.1.], v. 24, p. 1724, 1990. 
FREIRE, P. Pedagogia dell'autonomia. Torino: EGA, 2014.

GALlERIE NAZIONALI. Tratto da Gallerie Nazionali Barberini e Corsini. 2020. Available in: https://www.barberinicorsini.org/. Access on: 06/29/2021.

IABICHINO, G. Educare lo sguardo, tesi di laurea in matematica. 2019. Dissertation (Magistrale in Matematica) - Sapienza Università di Roma, Dipartimento di Matematica, Rome, 2019. Available in: http://programmi.wdfiles.com/local--files/matematica-e-arte/IABICHINO.pdf. Access on: 06/29/2021.

KLINE, M. Mathematics in Western Culture. New York: Oxford University Press, 1953.

LAKATOS, I. Proofs and refutations. Cambridge: Cambridge university press, 1976.

LLOYD, S. Cyclopedia of Puzzles. New York: The lumb publishing company, 1914.

MORIN, E. Une tête bien faite: Repenser la réforme, réformer la pensée. Paris: Éditions du Seuil, 1999.

ODIFREDDI, P. G. Il computer di Dio: Pensieri di un matematico impertinente. Milano: Raffaello Cortina, 2000.

ORTEGA Y GASSET, J. The revolt of the masses. New York: Norton \& Company, 1932.

PERROTTA, A. Laboratori interdisciplinari come metodo di insegnamento della matematica. Tratto da Conferenza al Congresso Nazionale dell'Unione Matematica Italiana. 2019. Available in: http://programmi.wdfiles.com/local--files/umi/AnnaP.pdf. Access on: 06/29/2021.

POLYA, G. Mathematical Discovery. On understanding, learning and teaching problem solving (Combined edition) New York: John Wiley \& Sons, 1981.

POPPER, K. Objective knowledge. An evolutionary approach. Oxford: Clarendon Press, 1972.

POSSAMAI, E. Un laboratorio per educare lo sguardo. Tratto da Conferenza al Congresso Nazionale dell'Unione Matematica Italiana. 2019. Available in: http://programmi.wdfiles.com/local-files/umi/ElenaP.pdf. Access on: 06/29/2021.

PUZIO, M.; SAVINELLI, E. Educare all'argomentazione. Tratto da Slide della conferenza al Congresso Nazionale dell'Unione Matematica Italiana. 2019. Available in:

http://programmi.wdfiles.com/local--files/umi/ElenaMaria.pdf. Access on: 06/29/2021.

ROGORA, E. Evaluating and choosing: the role of Mathematics. Lettera Matematica, [s.1.], v. 1, n. 4, p. 161-164, 2014.

ROGORA, E. Insegnamento Interdisciplinare. Conferenza all’Università di Camerino. 2018. Available in: http://programmi.wdfiles.com/local--files/matematica-e-arte/Camerino2018.pdf. Access on $06 / 29 / 2021$

SFARD, A. There is more to discourse than meets the ears: looking at thinking as communicating to learn more about mathematical learning. Educational studies in mathematics, [s.1.], v. 46, p. 13-57, 2001 .

STYLIANIDES, A. J. Proof and proving in school mathematics. Journal for Research in Mathematics Education, [s.1.], v. 38, n. 3, p. 289-321, 2007. 
TOROSSIAN, C.; VILLANI, C. 21 Mesures pour l'enseignement des mathématiques. Paris: Ministère de l'Education Nationale, 2018.

VASSALLO, V. Lo sguardo, genesi di un'idea per cambiare in profondità l'insegnamento della matematica. 2018. Available in: http://programmi.wdfiles.com/local--files/congresso/Vassallo.pdf. Access on: 06/29/2021.

Submetido em 13 de Setembro de 2019. Aprovado em 04 de Dezembro de 2020. 